\title{
The Study on the Teaching of the Basic Meaning of Chinese Directional Complement for Native English Speakers
}

\author{
Qianwen Zhou \\ Zhejiang Shuren University, Hangzhou 310015, China \\ E-mail: 2980946726@qq.com
}

\begin{abstract}
Learning and mastering the basic meaning of the directional complement is an important content of Chinese language learning for native English speakers, and it is also an important basic knowledge for them to learn Chinese well. There exist two reasons why the directional complement is difficult to learn. On the one hand, the grammatical structure is complicated since it is not only necessary to consider whether there is an object behind the verb of the directional complement, but also the position of the object and the directional complement. On the other hand, the semantic relationship is complicated because the directional complement has both basic and extended meanings. As the most basic meaning of directional complement, it is shared by all directional complements. Therefore, we should teach the directional meaning of directional complement.
\end{abstract}

Keywords: Directional Complement; Native English Speaker; Comparative Analysis; Teaching Strategy

\section{Introduction}

At present, there have been many discussions in the academic circles on the acquisition, error analysis and teaching strategies of directional complements in teaching Chinese as a foreign language. However, there is little discussion about a common difficulty in the study of Chinese by native English speakers, which is the basic meaning of the Chinese directional complement and its application. Learning and mastering the basic meaning of the directional complement is an important content of Chinese language learning for native English speakers, and it is also an important basic knowledge for them to learn Chinese well. As the most basic meaning of directional complement, it is shared by all directional complements. Therefore, teaching research on the basic meaning of Chinese directional complements is of great significance to promoting Chinese teaching as a foreign language.

\section{The directional meaning of Chinese directional complement}

A directional complement refers to a directional verb that serves as a complement after a verb or adjective. Its main function is to supplement the previous verb. The directional meaning is the basic meaning of the directional complement, which is the meaning represented by the directional verb itself as the directional complement, which indicates the direction of movement of people or objects in space through actions. Liu Yuehua came to the conclusion that there are three grammatical meanings of directional complement: direction, result and state in the book called Directional Complement Interpretation (1998). She believes that all directional complements can express directional meaning, that is, basic meaning; most directional complements can express resultant meaning, a few trend complements can express state meaning and the latter two are extended meaning of directional complements. Directional complements are complements by directional verbs, which represent the meaning of things moving with actions. Directional verbs are generally divided into two categories. One is that a single directional verb acts as a complement to form a simple directional com-

Copyright (C) 2020 Qianwen Zhou

doi: 10.18282/le.v9i7.1480

This is an open-access article distributed under the terms of the Creative Commons Attribution Non-Commercial License

(http://creativecommons.org/licenses/by-nc/4.0/), which permits unrestricted non-commercial use, distribution, and reproduction in any medium, provided the original work is properly cited. 
plement, such as “来, 去, 进, 出, 上, 下", etc.; the other is a compound directional complement, which consists of a directional verb The formed composite structure form, such as "上来, 起来 " and so on. The compound trend complement not only refers to the direction meaning of the trend, but also indicates the result of the behavior or the realization of the purpose.

\section{A comparative analysis of ways of expressing direction in Chinese and English}

\subsection{Ways of expressing direction in English}

There are three meanings in English: original meaning, figurative meaning and idiomatic usage. The structure of the directional meaning sometimes expresses the literal meaning of the directional verb itself, which is the meaning represented by the core verb and the small particle word in the sentence. The two meanings form a complete meaning through the logical combination of meanings and the small particles often have the directional meaning such as "bring in" ," spill over"," bring out"," take in" and " take out" . In the expression of extended meaning, in the collocation of core verbs and particles, particles often play a role in enhancing meaning, and often modify and strengthen the meaning of verbs such as"stay over", "eat up", “tie up"and"use up".

\subsection{A structural comparison of the directional meaning in Chinese and English}

\subsubsection{The structure of Chinese directional complement}

Although there is no uniform definition of the directional complement in academic circles, there is a general consensus to a certain extent. According to Liu Yuehua's description in Directional Complement Interpretation, the 28 directional complements are divided into two categories: simple directional complements and compound directional complements. As shown in theTable1below :

Table1 Summary of simple directional complements and compound directional complements

\begin{tabular}{|c|c|c|c|c|c|c|c|c|c|c|c|}
\hline $\begin{array}{c}\text { Simple directional } \\
\text { complements }\end{array}$ & 来 & 去 & 上 & 下 & 进 & 出 & 回 & 过 & 起 & 开 & 到 \\
\hline $\begin{array}{c}\text { Compound directional } \\
\text { complements }\end{array}$ & & & 上来 & 下来 & 进来 & 出来 & 回来 & 过来 & 起来 & 开来 & 到 ... 来 \\
\cline { 2 - 17 } & & & 上去 & 下去 & 进去 & 出去 & 回去 & 过去 & & 开去 & 到... 去 \\
\hline
\end{tabular}

\subsubsection{The structure of English directional complement}

There are two fixed forms in English that correspond to the meaning of Chinese directional complements. One form is that the verb itself expresses the directional meaning. For example, verbs like "arise, descend, depart" not only express the meaning of the verb, but also indicate the directional meaning of the verb. The other is the form of "verb + auxiliary verb"such as "She looked at the picture." and "The music began to hot up."

\section{Teaching strategies for native English speakers to acquire the basic meaning of the directional complement}

\subsection{To strengthen comparative teaching between Chinese and English and to predict teaching difficulties}

There are many differences in form and meaning between English and Chinese, but there are also many similarities. At the initial stage of learning Chinese, students will inevitably compare Chinese with their mother tongue, which is prone to negative transfer of mother tongue. The quality and basic skills that a Chinese teacher should have, a book written by Lu Jianming and Ma Zhen suggests that when considering the question of "what to teach", it is necessary to consider the grammatical similarities and differences between the Chinese language ( the target language) and the students' mother tongue. It is necessary to think about where both of them have in common, but also to distinguish the main differences, and which differences will particularly affect students' Chinese learning. It is necessary to think about where both of them have in common, but also to distinguish the main differences, and which differences will particular- 
ly affect students' Chinese learning. The systematic comparative study of Chinese and English by teachers can reduce the negative hindrance caused by the negative transfer of the mother tongue, then use the positive transfer of the mother tongue to promote the learning of Chinese.

Although there are similarities between Chinese and English expressions, there are also some differences. By conducting a comparative study of them, teachers can clearly understand the differences between the expression of Chinese and English, which will contribute to predict the difficulties that students may encounter in the learning process. As a result, designing teaching strategies on the basis of the mistakes that students often make will greatly improve their Chinese. For students, the systematic comparison between Chinese and their mother tongue in the expressions of directional complements can answer their doubts that often arise due to the interference of their mother tongue expressions, which will help students remember this part of knowledge more accurately.

\subsection{To follow the law of acquisition and arrange the teaching sequence reasonably}

The directional meaning of the directional complement is the grammatical meaning shared by all directional complements, so we should teach the directional meaning of the directional complement firstly. When teaching Chinese tending complements for native English speakers, we must follow the principle from shallow to deep. If the knowledge points are instilled into the students, the students not only do not understand, but also have a fear of difficulties. As we all know, the basic meaning belongs to the simpler one of the three grammatical meanings of the directional complement and it is also the first meaning that students come into contact with when learning the directional complement. Only when students understand and use the basic meaning of directional complements can they lay a good foundation for the subsequent learning of extended meanings. Similarly, the teaching strategies of teachers have an important impact on students' learning. When we explain the basic meaning of directional complements, we must let students master simple directional complements and then let them learn compound directional complements according to the students' acquisition rules. In addition, in the teaching of simple complements, the teaching of “来 " and " 去 " should be put in the first place, and then the teaching other directional complements. When " 来 / 去 " are used as directional complements, there are two knowledge points, one is a foothold and the other is a movement of direction. "来 " means that the direction of movement is toward the speaker's position (foothold), " 去 " means that the direction of movement is behind the speaker's position (foothold). When we teach “来 / 去 ", we can use flexible teaching methods, such as action demonstration, simple strokes and exercises.

In short, for native English speakers, the level of mastery of Chinese directional complements are related to the difference between directional complements and English prepositions. The smaller difference between the directional complement and the English verbal structure, the easier it is for native English speakers to master the directional complement. When teaching native English speakers Chinese directional complement, we should follow the principle from shallow to deep and step by step. When discussing the teaching strategies of basic meaning of directional complement, this article argues that the teaching of directional complement should focus on the comparison of grammatical structure, but it does not mean that semantics can be ignored because many students did not understand the basic meaning of the directional complement when they started to learn Chinese if the problem of "foothold" was wrong. The structure and semantics of directional complement are vital and either of them cannot be ignored.

\section{References}

1. Feng Jun. Supplementary Teaching of Chinese as a Foreign Language from a Cognitive Perspective [D]. Zhejiang University,2012.

2. Li Hui. The Symmetry and Asymmetry of "Coming/going” tendency [D]. Guangxi Normal University,2008.

3. Huang Yuehua. Polysemous Research on Chinese Tendency Verbs [D]. Hunan Normal University,2011.

4. Hao Xingyu. Research on the Tendency of "upper" and "lower" Modern Chinese to Complement as a Foreign Language Teaching [D].Suzhou University,2017)

5. CAI Bijun. Error Analysis and Teaching Strategies of Chinese Complement acquisition by Native English speakers [D].Shanxi University,2016. 
6. Lu Fang. Study on the Acquisition of compound Tendency of Complement "Rise" in middle and advanced stage overseas Students [D].Jiangxi Normal University,2012.

7. Yuan Pengkai. Error Analysis and Teaching Countermeasures of Chinese Tendency Complement for Foreign Students with English as their mother tongue [D].Liaoning Normal University,2018.

8. Wang Zhao. Comparative Study on the extended meaning of trend Complement "Rise", "go up" and "come out" [D]. Liaoning Normal University,2013.

9. Zhu Yuan. Comparative Study on Cognitive Semantics of Chinese-English Visual Vocabulary [D]. Shanghai International Studies University,2011. 